\title{
La memoria histórica en los libros de texto escolares
}

\section{Historical memory in school textbooks}

\author{
Enrique Javier DÍEZ GUTIÉRREZ \\ Universidad de León
}

Recibido: Marzo 2013

Aceptado: Abril 2013

\begin{abstract}
Resumen
Este artículo describe los resultados de la investigación llevada a cabo por la Universidad de León, financiada por el Ministerio de Presidencia, cuyo objetivo ha sido analizar cómo reflejan los libros de texto de Historia de España los contenidos correspondientes al período de la posguerra civil y especialmente los relacionados con la represión de la dictadura franquista y la lucha antifranquista. Se han revisado los manuales de texto, especialmente los de $2^{\circ}$ de Bachillerato, por ser el período curricular en el que se trabaja más detenidamente la Historia contemporánea de España. Metodológicamente se ha utilizado el Análisis Crítico del Discurso para indagar sobre la extensión y completud, así como sobre la orientación y visión que presentan de los contenidos, y se han realizado 610 entrevistas a profesorado de Historia sobre su percepción respecto a la adecuación de estos contenidos. Las conclusiones más significativas reflejan que se han empezado a introducir contenidos sobre estos aspectos, aunque no con la suficiente profundidad.
\end{abstract}

Palabras clave: Memoria Histórica; Historia de España; Libros de texto; Represión franquista; Lucha antifranquista.

\begin{abstract}
This article reports the results of a study conducted at the University of León, Spain, and funded by the Spanish Ministry for the Presidency. The aim of this research study was to analyze how history textbooks in Spain present the subject of the post civil war era, particularly those aspects related to repression under the Franco regime and anti-Francoist resistance. A review of textbooks was conducted, focusing especially on those used for 2nd year of Bachillerato (upper secondary education), since it is the course where Spanish Contemporary History is studied more thoroughly in the curriculum. A Critical Discourse Analysis approach has been adopted to investigate the extent, completeness, orientation and perspective of the content presented. In addition, 610 history teachers were interviewed in order to gather their opinions regarding the adequacy of the contents presented. The most significant findings indicate that although content related to these topics has begun to be included, the subject is not covered in sufficient depth. Keywords: Historical Memory; History of Spain; Textbooks; Francoist Repression; AntiFrancoist Resistance.
\end{abstract}


El estudio de la Historia es reconocido como un elemento fundamental de la actividad escolar por su valor formativo al referirse al estudio de la experiencia humana a través del tiempo (Cuesta, 1998). El pasado conforma muchos de los esquemas de conocimiento e interpretación de la realidad al estar presente en nuestra vida actual, tanto individual como colectiva. La perspectiva temporal y el enfoque globalizador, específicos de esta disciplina, proporcionan conocimientos relevantes sobre ese pasado que ayudan a la comprensión de la realidad actual. A su vez contribuyen a mejorar la percepción del entorno social, a construir una memoria colectiva y a la formación de ciudadanos y ciudadanas responsables y conscientes de sus derechos y de sus obligaciones para con la sociedad. Su estudio debe servir para profundizar en el conocimiento de la herencia personal y colectiva (Mudrovcic, 2005).

El material fundamental para el estudio de la Historia son los manuales escolares. Los textos escolares dominan el curriculum: la mayor parte del tiempo escolar se centra en torno a ellos, tanto del alumnado como del profesorado (Apple, 1986). De ahí su importancia: ayudan a construir el imaginario colectivo de las futuras generaciones, la comprensión que se hace y la perspectiva que se adopta sobre el pasado, el presente y el futuro, así como las conexiones con las causas y razones que han motivado las acciones humanas a lo largo de la historia (Díez Gutiérrez, 2007).

Pero cuando una parte del equipo de investigación, participamos en la producción y realización del documental "Los campos del silencio", sobre los presos republicanos en campos de concentración franquistas, constatamos que la mayor parte de los adolescentes y jóvenes del Instituto de Secundaria de Fabero del Bierzo (León) que participaron en la grabación del mismo, desconocían o conocen esta parte de la historia de una forma fragmentada e inconexa. Parecía que sus libros de texto, sus clases de historia, su formación académica, la reconstrucción histórica que se les brindada en el ámbito escolar, todavía seguía encubriendo, silenciando u ocultando de forma significativa esta parte de la historia que nos pertenece a todos y todas, a la sociedad en su conjunto.

En la última parte del documental se les preguntaba, durante la grabación, sobre el campo de concentración que había estado ubicado en su pueblo, en el que hubo un batallón de unos 250 presos republicanos, de 1939 a 1947, trabajando como "esclavos" para una empresa privada (Minas Moro) en la extracción de carbón en las minas del Bierzo. No sólo desconocían que en su propio pueblo hubo uno de estos campos de trabajo forzados, sino que no les habían contado ni siquiera que algunos de sus abuelos habían estado ahí presos y que sus abuelas y todos los familiares de estos presos habían sufrido la represión franquista durante largos años en el pueblo. Cuando fuimos con estos alumnos y alumnas de bachillerato al sitio donde había estado el campo de concentración y se les explicó lo que allí había pasado y lo que esto supuso, así como la lucha que una parte de sus mayores había seguido librando contra el franquismo, se produjo una especie de conmoción ante la sensación de que se les había ocultado buena parte de su propia historia.

De esta experiencia surgió este proyecto de investigación con el fin de analizar los contenidos que sobre esta época se estaban dando en las clases de Historia a nuestro 
alumnado, los materiales curriculares que estaban empleando el profesorado y los conocimientos que realmente estaban aprendiendo. Pues si el documental se centraba en los mecanismos de construcción social de la inconsciencia colectiva, de ese silencio, miedo y olvido que aún hoy en día se puede sentir en donde ocurrieron los hechos y donde viven los descendientes de muchos de aquellos presos, queríamos analizar si los contenidos de los libros de texto correspondiente a la historia de España reflejaban lo que fue y supuso la represión franquista y la lucha antifranquista o si por el contrario contribuían a ocultar o silenciar y minimizar esta parte de la Historia.

\section{Estado de la cuestión}

Desde un enfoque educativo crítico, es manifiesto que todos los contenidos científicos o escolares son provisionales, en constante discusión y cargados de la ideología que subyace a sus impulsores y al contexto histórico y social de su producción. Más aún en el caso de los contenidos históricos, siempre sometidos a cuestionamiento y revisión, especialmente aquellos más cercanos y controvertidos por el grado de enfrentamiento que supuso y las distintas visiones que se han dado respecto a ellos. Diversos autores y autoras concluyen que la Historia que pervive es la historia de los vencedores, de sus logros, y es ese enfoque el que queda recogido fundamentalmente en los libros de texto de Historia (Álvarez Osés, 2000)

La recuperación de la Memoria Histórica suscita reacciones muy encontradas entre la esfera política y social en España (Pérez Garzón y otros, 2000; Ruíz Torres, 2007; Vinyes, 2011). De hecho, el propio Congreso de los Diputados y Diputadas continúa sin atreverse a condenar el régimen Franquista, ni a exigir una aplicación de la Ley de Memoria Histórica con todas sus consecuencias ${ }^{1}$ (Terradillos, 2010). Sin embargo la Comisión de Derechos Humanos de las Naciones Unidas estableció el 17 de abril de 1998 que el "derecho a saber", en tanto que derecho colectivo, implica, por un lado, el derecho inalienable a conocer la verdad de lo que ocurrió y, por otro, el "deber de recordar".

Por eso, aunque se han realizado numerosas investigaciones y publicaciones especializadas sobre este período y sobre estos acontecimientos que han vertido mucha luz sobre los mismos, lo cierto es que "no ha terminado de formar parte, precisamente debido a esa carencia, de una percepción colectiva sobre el pasado" (Rodrigo, 2006, 19). Porque, como recuerda este autor, esa denominada "falsa memoria" del franquismo parece seguir presente en muchos aspectos de la vida cotidiana, desde las series televisivas hasta los libros de texto escolares.

No podemos olvidar que la guerra civil española marcó tanto la memoria de sus protagonistas, directos e indirectos, como la de sus descendientes y la de las generaciones futuras. Porque la guerra civil y la represión posterior constituyen "un

\footnotetext{
1 Todavía hoy no se han condenado, ni anulado los juicios sumarísimos bajo jurisdicción militar de la dictadura franquista, ni se ha asumido como labor del Estado la exhumación de las víctimas del franquismo, por ejemplo.
} 
pasado que no acaba de pasar" (Rodrigo, 2006), cuyo lastre y heridas siguen muy presenten no sólo en quienes lo sufrieron y en sus familias, sino en la visión colectiva heredada del franquismo. No solamente debido, como dice Ruiz-Vargas (2006), a la crueldad de los tres años de guerra y los cuarenta años siguientes de sistemática represión por la dictadura, mediante el terror institucionalizado y la violencia bajo diferentes formas en la que se implicó activamente una parte de la sociedad civil (la que se sentía vencedora), sino porque todas las víctimas de la violencia represiva de una dictadura sufrieron una doble ofensa: la agresión de sus verdugos y la tortura psicológica de intentar borrarlos de la memoria.

En la última década el interés por reflexionar sobre nuestro pasado inmediato que se ha extendido en nuestra sociedad (Traverso, 2007), se debe, ciertamente, a que todavía hoy la memoria pública y colectiva difiere sustancialmente de las conclusiones a las que nos conducen los estudios históricos y la memoria individual silenciada (Carretero, Rosa y González, 2006). Desde sus inicios, la dictadura franquista desarrolló una política de la memoria que procuró por todos los medios demonizar, y posteriormente hacer desaparecer, la memoria de la Segunda República y así poder consolidar una nueva memoria colectiva afín a sus propósitos. La maquinaria del silencio y la negación, cuyo fin último es el olvido, buscaba un completo dominio sobre la memoria, la cancelación del recuerdo y la imposición de los paradigmas oficiales (Levi, 1986).

La transición a la democracia traía consigo cuarenta años de asentamiento de ese "inconsciente colectivo", de recreación constante de los postulados franquistas sobre el origen de la guerra civil, la barbarie "roja" y la necesidad del "orden" franquista. Durante este período de transición, la supuesta "necesidad de consolidar el régimen democrático" y el miedo y control generado por la continua alusión al "ruido de sables", condicionó la posibilidad de desarrollar una política de la memoria que enlazase con la tradición democrática republicana (Reig Tapia, 2009, 108).

Tampoco cuando la democracia ya estuvo consolidada, los gobiernos sucesivos tuvieron interés en desarrollar una política de la memoria basada, no sólo en la exaltación de los valores democráticos sino, también, en la reivindicación de aquéllos que habían luchado contra el franquismo y que, con su esfuerzo, fueron una pieza esencial en la instauración de la actual democracia. Es decir, durante mucho tiempo, la falsa memoria recreada por el franquismo no se vio contrarrestada institucionalmente con una nueva política de la memoria sustentada en referentes democráticos pasados y presentes (Molinero, 2004). De esta forma los valores de los perdedores y las perdedoras de la guerra fueron excluidos del imaginario colectivo y de la representación social del pasado, quedando su memoria proscrita al ámbito individual o familiar. Lo cierto es que el "memoricidio", como fue descrito por Primo Levi, que intentó llevar a cabo el franquismo ha sobrevivido décadas al final de la propia dictadura, mediante una suerte de cultura del miedo y del silencio (Rodrigo, 2006), que aún se saca a la luz nada más que se agitan un poco las demandas de justicia o de reparación histórica de las víctimas. 
No obstante, la situación parece haber cambiado un tanto. La sociedad, especialmente entre la generación de "los nietos y las nietas de la guerra", lucha hoy por sacudirse la interiorización de esa "amnesia colectiva". Vuelve su mirada hacia esa historia oscura de represión y barbarie, reclamando conocer la magnitud de la represión y exigiendo que se reconozca moralmente a las víctimas. Las instituciones lenta y muy moderadamente están recogiendo esa demanda social; la aprobación de la Ley por la que se reconocen y amplian derechos y se establecen medidas a favor de quienes padecieron persecución o violencia durante la Guerra Civil y la Dictadura, va en este sentido.

Este relativo impulso a la recuperación de la memoria democrática por parte de las instituciones no implica de ninguna manera participar en la confrontación de memorias, sino asegurar la incorporación del conocimiento riguroso del pasado a la memoria pública, lo que en el caso español supone transmitir a las nuevas generaciones el significado de la Segunda República, el franquismo y el antifranquismo a la luz de los valores democráticos. Una política pública de la memoria debe tener como objetivo proclamar solemnemente la vigencia de los valores democráticos por lo que vivieron y, tantas veces, murieron los que defendieron la República, como fundamento de la organización y convivencia social actual. Y el espacio privilegiado por el que las jóvenes generaciones pasan y conocen nuestra historia es el ámbito escolar.

\section{Método e instrumentos}

La pretensión de esta investigación se ha enfocado al estudio de los materiales curriculares y libros de texto que utiliza el alumnado, especialmente en Educación Secundaria Obligatoria y Bachillerato (de 12 a 18 años) de todo el Estado español para analizar los contenidos que en ellos aparecen sobre las consecuencias de la guerra civil, la represión franquista y la lucha antifranquista, así como el movimiento de recuperación de la memoria histórica actual, indagando sobre su extensión, orientación, completud y visión, en varias dimensiones: a) La proporción destinada a este período histórico en relación con el destinado a otros períodos de la historia de España. b) Los aspectos resaltados y destacados, frente a aquellos silenciados u ocultados. c) La visión que se plantea en los mismos sobre las víctimas de la guerra civil y del franquismo. Se ha realizado simultáneamente una investigación complementaria con el profesorado de historia de Secundaria y Bachillerato sobre su percepción respecto a la adecuación de los contenidos en los libros de texto y materiales curriculares complementarios que tratan el período de la guerra civil, las víctimas de la misma y del franquismo y la lucha antifranquista.

Hemos aplicado el Análisis crítico de contenido (Van Dijk, 1997) a todos los manuales de Historia, desde primaria hasta bachillerato, para indagar cómo transmitían no sólo los datos y acontecimientos sobre el período destinado a la II República, sino especialmente los contenidos, actividades e ilustraciones dedicados a la represión franquista y a la lucha antifranquista tras la guerra civil. 
El objetivo del Análisis crítico de contenido (Van Dijk, 2008) ha sido lograr la emergencia del sentido latente que subyace en los componentes semánticos y formales plasmados en los libros de texto escolares. La parte cuantitativa se ha centrado en los elementos cuantificables: los aspectos formales y el contenido manifiesto no sólo de los textos propiamente dichos, sino también de las imágenes analizando situación, tamaños, proporciones, relación, etc. La parte cualitativa se ha centrado más en el contenido latente, desarrollando una labor propiamente interpretativa, no limitándonos pues a las estructuras textuales o icónicas, sino profundizando más allá en el análisis de los diversos significados, opiniones o ideologías que sustentan las mismas (Krippendorf, 1990). Tenemos que tener en cuenta que el análisis crítico de contenido toma prestados aspectos esenciales del enfoque del Análisis crítico del discurso que analiza cómo la dominación se reproduce y se resiste con los discursos (Fairclough, 1992; Fairclough, 1992a; Fairclough, 2008). Este enfoque concibe el discurso, por un lado, como un producto "susceptible de revelar determinados contenidos subyacentes (visiones del mundo, opiniones, ideologías)" y, por el otro, como un instrumento "capaz de proyectar esos contenidos en las representaciones sociales o individuales de las personas". El interés principal del ACD proviene de esa doble funcionalidad atribuida al discurso. Si éste es visto como un producto y como un instrumento capaz de reflejar visiones sociales pero también de cambiarlas e incluso en algunas ocasiones de crearlas, la nota que define y diferencia este tipo de análisis de otros que se incluyen en este campo es la intención de desvelar las complicadas relaciones que se establecen entre las estructuras de poder, las ideologías y los discursos a través de los cuales se configuran los dos elementos anteriores (Van Dijk, 1997). Por eso el análisis que hemos realizado de los libros de texto no se centra en todos los aspectos lingüísticos del discurso de los libros de texto sino solo en aquellos que estén revestidos de una función de ideológica, y más concretamente, en aquellos a través de los cuales se pueda demostrar cómo los grupos dominantes emplean las prácticas discursivas para lograr sus intereses.

También hemos diseñado y aplicado entrevistas semiestructuradas para conocer la percepción que tiene el profesorado de Historia de ESO y Bachillerato respecto a la adecuación de los contenidos relacionados con las consecuencias de la Guerra Civil, la represión franquista y la lucha antifranquista en los libros de texto y materiales curriculares complementarios, en cuanto a su completud, su extensión, su orientación y visión, así como si la proporción destinada a este período histórico en relación con el destinado a otros períodos de la historia de España es la adecuada y si es adecuada la visión que se plantea en los mismos sobre las víctimas de la guerra civil y del franquismo.

Se utilizaron la inducción analítica (Znaniecki, 1934; Robinson, 1951), la codificación (Taylor y Bogdan, 1992) y las comparaciones constantes (Glaser y Strauss, 1967) durante el proceso de análisis e interpretación de los datos recogidos. De la triangulación de los datos analizados, tanto cualitativa como cuantitativamente, se han elaborado las conclusiones finales. 


\section{Muestra}

Aunque, como se ha comentado, nos centramos más en segundo de bachillerato, puesto que es el curso donde más se desarrolla y estudia este período histórico, según el curriculum oficial vigente, también exploramos que contenidos se imparten sobre este período histórico en cuarto de la educación secundaria obligatoria, dirigidos a alumnado de entre quince y dieciséis años, para analizar el enfoque y extensión que se le da a los mismos (Sánchez-Lafuente Recena, 2008). Lógicamente, en primaria, dada la generalidad y escasez con la que se abordan estos contenidos, ligados a una visión relacionada con otros aspectos sociales y culturales, sólo se hizo un análisis de algunos de los libros de texto más emblemáticos, pero no se hicieron entrevistas al profesorado de primaria, dado que en general tampoco son especialistas en el ámbito de la Historia. No obstante, constatamos que ya se intuye la orientación que va a predominar en los cursos superiores sobre estos temas.

La muestra inicial objeto de estudio se dividía en dos ámbitos. Por un lado, mediante entrevistas semiestructuradas hemos requerido la opinión de profesorado del área de Historia que imparte su docencia en esta materia en Institutos de Secundaria. Por otro lado, mediante análisis crítico del discurso, exploramos los libros de texto que se utilizan más frecuentemente en los centros escolares actualmente.

En el primer ámbito, hemos entrevistado a 610 profesores y profesoras de diferentes Institutos de Secundaria, tanto públicos como privados-concertados, de diferentes Comunidades Autónomas del Estado español, teniendo en cuenta la diversidad geográfica (zonas rurales, urbanas y semiurbanas o periféricas de las grandes ciudades) y poblacional (institutos grandes, con alumnado matriculado entre 800 y más de 1.000; institutos medianos, con alumnado entre 400 y 800 ; e institutos pequeños, con menos de 400 alumnos y alumnas).

Se ha explorado en una media de 12 centros por provincia de todo el territorio (aunque en la Comunidad de Castilla y León han sido más, puesto que la mayoría del equipo de investigación pertenecía a esta comunidad). Buscábamos así que hubiera, al menos, una muestra representativa de la mayor parte de la geografía estatal y de los distintos tipos de centros educativos de la misma.

Dado que los centros de Secundaria y Bachillerato de todo el Estado son un total de 6.026, según datos del Ministerio de Educación en el curso 2010-2011, el porcentaje de departamentos de historia a los que se ha realizado la entrevista ha sido del $10 \%$ de la población objeto de estudio. Se ha mantenido en la muestra de entrevistas la proporción entre centros públicos y privados-concertados que hay a nivel estatal (3.932 públicos y 2.094 privados-concertados, según datos del Ministerio de Educación para el curso 2010-2011): de esta forma, se ha entrevistado un 65\% profesorado de centros públicos y un $35 \%$ de profesorado de centros privados-concertados. 
El hecho de haber recogido una muestra tan amplia entre el profesorado, y de tal diversidad de centros que han participado, nos da un alto grado de fiabilidad de los resultados de esta investigación ${ }^{2}$.

En el segundo ámbito, hemos revisado 21 libros de texto de distintos años y niveles escolares. Pero para la muestra de esta investigación nos hemos decantado por seleccionar y analizar las ediciones más recientes de los libros de texto más utilizados en las asignaturas de Historia de España de $4^{\circ}$ de la ESO y de $2^{\circ}$ de Bachillerato. De ahí que, aunque se citen a veces ediciones anteriores o manuales de niveles diferentes, que nos pudieran parecer significativos por su relevancia o su oportunidad para explicar el aspecto al que se haga referencia, la muestra considerada se ciñe a lo anteriormente señalado.

Para establecer dicha muestra, tras hacer una revisión exhaustiva de los libros de texto más utilizados en las diferentes comunidades autónomas y confirmar esta revisión con las respuestas ofrecidas por el profesorado entrevistado, a través de la pregunta en la entrevista que se les hizo sobre los textos y editoriales que utilizaban en sus centros, se seleccionaron para el análisis las 10 editoriales de ámbito nacional más utilizadas que autorizaron realizar dicho análisis: Oxford, McGraw Hill, SM, Vicens Vives, Santillana, Anaya, Laberinto, Bruño, Ecir, Akal. De estas editoriales se han examinado 21 libros de texto: 12 correspondientes a $2^{\circ}$ de Bachillerato y 9 a $4^{\circ}$ de la ESO.

En cada uno de los libros de texto se ha analizado la parte correspondiente al período comprendido entre el estallido de la guerra civil, en 1936, y el final de la lucha antifranquista en las postrimerías de la dictadura. En general, dado que este período se agrupa en dos unidades temáticas (guerra civil y franquismo) son en las que se ha centrado el estudio. No obstante, señalar que en algunos libros de texto, la segunda unidad puede estar divida en dos subunidades, por lo que el análisis comprendió los tres temas en estos casos.

\section{Resultados}

Se exponen a continuación los resultados principales de este estudio a partir de la triangulación de los dos instrumentos de investigación aplicados: análisis crítico del discurso de los libros de texto y entrevistas con el profesorado de historia.

El primer resultado significativo indica que buena parte de estos materiales curriculares sí recogen, aunque no con la suficiente profundidad, una parte significativa de los hechos que se desarrollaron tras el fracaso de la experiencia republicana en los años 30 en España, especialmente los relacionados con la represión de la dictadura franquista y la resistencia de muchos hombres y mujeres frente a ella.

\footnotetext{
${ }^{2}$ Para un nivel de confianza del $95,5 \%$ (dos sigmas), y $\mathrm{P}=\mathrm{Q}$, el error real es de $\pm 3,75 \%$ para el conjunto de la muestra y en el supuesto de muestreo aleatorio simple.
} 
Es de destacar que no ha sido hasta las últimas ediciones revisadas cuando se han introducido bastantes contenidos relacionados con la resistencia antifranquista de los hombres -las mujeres apenas son tenidas en cuenta-, pero resaltando sobre todo los movimientos y organizaciones de resistencia de corte más moderado. Por ejemplo, se dedican muchos más contenidos y atención a la resistencia política de los años 60 que a toda la lucha guerrillera durante los 20 años anteriores. No obstante, el libro de $2^{\circ}$ de Bachillerato de ECIR del año 2010, incorpora ya una referencia al libro Maquis del profesor Secundino Serrano.

Se tiende a olvidar o incluso se minimiza la represión franquista sistemática y orquestada legalmente y con carácter retroactivo que se prolongó durante los 40 años posteriores a la guerra civil. Solo el $44,4 \%$ de los manuales de $4^{\circ}$ de la ESO lo expresan así, es decir, menos de la mitad de los libros de texto que utiliza nuestro alumnado en la enseñanza obligatoria. El porcentaje se eleva hasta el $58,3 \%$ en $2^{\circ}$ de Bachillerato, pero seguimos estando muy lejos de que se haya asumido por toda la historiografía relevante que influye en la construcción de los contenidos de los manuales de bachillerato.

Incluso hay temas especialmente "tabú" que no se tocan ni siquiera "colateralmente", como el papel legitimador de la Iglesia en todo el proceso de represión (sólo aparece en la mitad de los libros de $2^{\circ}$ de Bachiller y $4^{\circ}$ de la Eso analizados) o los mecanismos "legales" de incautación de bienes de familias republicanas represaliadas (sólo aparece mencionado en la página 325 del libro de Historia de $2^{\circ}$ de Bachillerato Crisol de Vicens Vives de 2008; y en el de $4^{\circ}$ de ESO de Santillana del año 2005) y las consecuencias de ello, no sólo para la población que los sufrió, sino en el proceso de enriquecimiento y generación de nuevas fortunas que asentaron la oligarquía del régimen. Tampoco aparece en los libros de texto analizados, como así lo confirma también el profesorado entrevistado, la implicación activa de una parte de la sociedad civil (la que se sentía vencedora) en el plan de represión, intimidación y exclusión social de la dictadura franquista. Al igual que tampoco se hace prácticamente ninguna referencia al reconocimiento de las víctimas del franquismo y de quienes desde la lucha antifranquista siguieron defendiendo el orden legítimo de la II República.

El segundo resultado a destacar en la investigación hace referencia a la proporción de espacio dedicado a estos temas respecto al resto de temas en su conjunto. Los 43 años que duraron la II República, la guerra civil y la dictadura franquista ocupan una media del $39,4 \%$ de los contenidos del siglo XX en los libros de texto de $2^{\circ}$ de Bachillerato más utilizados por nuestro alumnado. Hemos de tener en cuenta que éste es el curso que dedica mayor extensión a desarrollar estos contenidos a lo largo de todo el período de escolarización. En comparación con la extensión que dedican los libros de texto a otros períodos de la historia, el volumen ocupado parece globalmente adecuado a su importancia y extensión temporal. Pero hay que señalar que, dentro de ese $39,4 \%$, el mayor espacio lo ocupa la descripción de la guerra civil, seguida por la época de la II República, sin embargo se dedica mucha menor proporción a la represión de la dictadura y a la lucha antifranquista. En cuanto a los movimientos de 
recuperación de la memoria histórica prácticamente están ocultos en los contenidos de los libros de texto.

La mayoría de los libros escolares se centran en detallar, amplia y pormenorizadamente, la parte referida a la guerra civil y a las diferentes batallas que se sucedieron durante la contienda. En cuanto a la represión posterior, es cierto que algunos hacen referencia a temas como los "paseos", pero, en general, las cunetas, las fosas y la represión sistemática y organizada de los sospechosos y de sus familias no están en la mayoría de los libros de texto. Igualmente, la historia de la resistencia antifranquista, aunque está presente en muchos de los libros de texto analizados, se trata de manera bastante superficial. Sólo se trata más extensamente en algunos de los libros de texto publicados más recientemente.

Un tercer resultado que podemos subrayar es que, en general, se habla de los "desmanes de ambos bandos" y la impresión general que queda, al final, supone una concepción simplista y en parte legitimadora, ligada a una visión de dos partes enfrentadas de las que ganó una que, lógicamente, se convirtió en la vencedora y, por lo tanto, administradora del nuevo régimen. Los contenidos relacionados con estos temas tienden a presentarse desde una visión supuestamente "neutral y aséptica", como hemos podido comprobar o, al menos, "políticamente correcta", pero que realmente encubre graves silencios y ocultamientos deliberados. Aparece así reiteradamente la concepción de que "todos fuimos culpables" de una forma u otra de la barbarie que vivió la España de los años 30. Es la denominada teoría de la equidistancia o equiparación (Erice, 2009), en la que se plantea que hubo un enfrentamiento entre dos bandos, una lucha fratricida entre hermanos, que marca con el signo de la "culpabilidad" por igual a las dos partes enfrentadas.

Un ejemplo de ello es el manual de la editorial Bruño de $4^{\circ}$ de la ESO, que afirma que "en el territorio republicano se desarrolló el Terror Rojo [...] muy virulento contra la Iglesia y contra los partidarios de los sublevados. En la zona nacional se impuso, más sistematizado, el Terror blanco, que represalió y fusiló a numerosas personas fieles a la República." (Bruño. 2008, 205). En el libro de la editorial Santillana se filtra la misma posición ideológica, reforzando la idea de que fue una guerra que enfrentó a "dos bandos", tal y como puede leerse en su manual de $2^{\circ}$ de bachillerato: "en los dos bandos hubo un fenómeno semejante: la voluntad de exterminar al adversario produjo un simultáneo terror" (Santillana, 1996, 311). Aunque en ediciones posteriores matiza un tanto este posicionamiento al afirmar "el conflicto militar no era inevitable, pero algunas características de la época nos ayudan a explicar su origen y desarrollo: las enormes diferencias sociales, el enfrentamiento religioso y la radicalización ideológica de las derechas y de las izquierdas" (Santillana. Serie İtaca. 2005, 223).

No obstante, hay que señalar que ya hay manuales más recientes que diferencian entre las "culpabilidades" y entre la tipología de las violencias y represiones, cuestionando esta teoría de la equidistancia. Esto lo hemos podido comprobar en el libro de texto de Vicens Vives de $2^{\circ}$ de bachillerato cuando señala que "la Guerra Civil fue más bien el enfrentamiento armado entre los viejos grupos dominantes de la España de la Restauración, cuyo instrumento fue el ejército, y los grupos emergentes 
obreros y burgueses que querían establecer un sistema político democrático y un orden social progresista (Vicens Vives, 2009, 348) o cuando afirma, en una edición anterior que "el alzamiento militar se intentó justificar con el argumento de que en la República gobernada por el frente popular se estaba preparando una revolución comunista dirigida por los sindicatos obreros, que eliminaría la propiedad privada, la religión y el Estado existente para imponer un soviet al estilo ruso. Nada de ello tenía fundamento: en la primavera de 1936 no había ninguna revolución en marcha" (Vicens Vives, 2003, 240).

En definitiva, como apunta Erice (2009), la teoría de la equidistancia es un tema fundamental, porque enlaza con toda la visión dominante del último franquismo y la transición y en el fondo está en cierto modo presente incluso en la denominada "ley de la memoria histórica". De hecho esta teoría viene ya del "segundo franquismo", cuando el relato de la cruzada deja de ser creíble y desde las filas del propio régimen empieza a hablarse, aunque con muchos matices, de "guerra entre españoles" o utilizando términos similares. Aunque los textos escolares de los años 60 y principios de los 70 introducen ya cambios importantes, este discurso se mantiene e impone en la Transición, llegando como vemos hasta nuestros días.

Un cuarto y último resultado señalado es que uno de los principales escollos que se ha detectado en las entrevistas con el profesorado, a la hora de tratar este tema en los libros de texto, es la resistencia por parte de éstos a admitir el término Memoria, o adaptar su significado, en el contexto de la Historia. Quizá se deba a la influencia de los especialistas en este campo académico, que son bastante reticentes a incorporar este enfoque y con sus publicaciones marcan poderosamente la mentalidad del profesorado de esta especialidad (Kingman, 2012). Es decir: se viene considerando historia como el campo de lo objetivo frente a la memoria como el campo de lo subjetivo, tomando ambos conceptos y ambas realidades como incompatibles y asumiendo que la historia contada por los especialistas, supone un plus de veracidad, que la memoria, ya sea colectiva o individual, no tiene.

En este sentido, es muy llamativo el comentario de Aranzadi (2009):

"La Historia no es nunca memoria. La Historia es siempre ideología, y lo es especialmente cuando se disfraza de ciencia, de registro y relato "objetivo" del pasado. Y las historias nacionales $o$ historias de naciones, las historias de España o de Alemania, son siempre el núcleo y fundamento de las ideologías nacionalistas que guían los usos políticos de la memoria histórica que sobre aquéllas se construye: los monumentos y conmemoraciones construidos y promovidos por los Estados Nacionales o los partidos y movimientos nacionalistas no son nunca recuerdo o memoria fiel del pasado, sino un estímulo ideológicamente dirigido de la imaginación de los individuos, incitación a superponer sobre la memoria individual una interpretación politicamente orientada del recuerdo, la actitud o la opinión personal” (p. 162). 
En la España redemocratizada, los políticos y científicos estaban de acuerdo en que no querían que hablasen más los abuelos que habían luchado en la guerra; ahora les tocaba a los jóvenes académicos que la conocían a través de las fuentes y la literatura. Se repetía que había que ser "objetivos" y "argumentar con distanciamiento histórico" porque el acontecimiento había ocurrido hacía mucho tiempo y ya formaba parte de la historia. Así, la transición constituyó un "pacto" que compensaba la entrega del poder por parte de los franquistas mediante la amnesia colectiva, tanto por parte de los gobiernos conservadores durante la transición de los años 1977 a 1982, como por parte del PSOE (Bernecker, 2009). Ese "pacto" establecía la necesidad de un olvido y perdón de todos los crímenes y barbaridades cometidas por los "dos bandos" en la Guerra Civil, antes de ella, en ella y después de ella, hasta nuestros días (Juliá, 2009).

La labor de las asociaciones de recuperación de la memoria histórica y de la generación de los nietos y nietas que han empezado a reivindicar la memoria histórica y a exhumar fosas comunes de represaliados por el franquismo, ha empezado a calar tímidamente en algunos libros de texto, pero más en las actividades escolares que propone el profesorado en sus aulas.

Si en Alemania, desde mediados de los 60, ha habido un cambio en la mentalidad de una parte de la sociedad, y ha sido la generación de los hijos la que ha comenzado a reivindicar una revisión de su historia, una revisión de los juicios a los criminales nazis, un análisis del "pasado reciente" y una oposición firme a la idea de "punto final" (Frei, 2009), en España ha sido la generación de los nietos la que ha reclamado justicia, ya que sus abuelos callaron por miedo, y sus padres por razones políticas (Reig Tapia, 2009). Estos nietos representan a una generación que "no participó en los pactos de la transición, que tiene bastantes referencias de lo que fue la dictadura franquista, que heredó en cierto modo las consecuencias de haber pertenecido a una familia republicana y que no tiene miedo de defender públicamente la memoria de sus ancestros" (Silva, 2009, 177).

\section{Conclusiones}

Como plantea Vinyes $(2004,6)$ los ciudadanos y las ciudadanas somos depositarios y herederos naturales de la historia, del recuerdo y la memoria. El olvido es el impedimento de acceso al conocimiento, es único y es sólido y tiene por objetivo que sólo se acepte una versión del pasado, para destruir así la memoria diversa; por eso las dictaduras tienen en el olvido el recurso imperativo y necesario que consolida su cultura, y por tanto su poder y su consenso. La democracia tiene que fomentar el acceso de la ciudadanía al conocimiento histórico porque es la única garantía de respeto a la pluralidad de memorias, permite la adquisición de criterios propios y hace a los ciudadanos y a las ciudadanas civilmente más sabios, y por lo tanto más libres. Las políticas institucionales de la memoria dicen mucho de los valores éticos y cívicos subyacentes en un sistema político (Aguilar Fernández, 2008). La memoria pública es crucial y necesaria. Por esa razón el conocimiento histórico ha sido considerado por muchos estados democráticos como un derecho civil que los gobiernos han de garantizar y promover (Vinyes, 2004). 
Por eso, se impone la necesidad de reconstruir un currículum contra-hegemónico que garantice la justicia curricular. (Re)construir un pasado dentro de un marco de referencia colectivo y desde el presente, de tal forma que la experiencia y las memorias de las personas olvidadas y desfavorecidas formen parte también del currículum oficial. Un currículum, construido a partir de la posición de los grupos subordinados, que invierta la hegemonía. No para "dar la vuelta a la tortilla", sino para proporcionar experiencias e informaciones desconocidas y olvidadas, para hacer un currículum más comprensivo, más representativo (Abós, 2004). Esto supone replantear la historia desde la perspectiva de los perdedores, de los grupos oprimidos, de los represaliados, de los olvidados. Y combinar las memorias de las víctimas con la historiografía más actual (Todorov, 2002). Porque, como nos recuerda Cuesta (2011a, 17) se ha producido un reordenamiento de las fronteras epistemológicas entre memoria e historia, volviéndose cada vez más borrosas al punto de que historiadores culturales como Chartier (2005) consideran tales delimitaciones territoriales como falsos dilemas del pasado incompatibles con las nuevas orientaciones de la historiografía. De ahí que Cuesta $(2007 ; 2011 b)$ abogue por una "historia con memoria", es decir, generar situaciones de aprendizaje donde la historia se desvista del código disciplinar tradicional y, siguiendo esa idea de ir a la búsqueda de los recuerdos, atienda a las voces del pasado, bien sea través de la captación del testimonio directo que favorece la historia oral, bien sea mediante la interpretación de documentos de muy diversa naturaleza.

Este enfoque de la enseñanza atiende a la historia desde abajo, desde la experiencia de los protagonistas, convirtiendo el conocimiento histórico en una realidad cultural controvertida y susceptible de ser sometida al escrutinio personal y público. Porque la utilidad principal de la "memoria colectiva" es el aprendizaje colectivo, la utilización del pasado (sobre todo, del traumático) como enseñanza para el presente mediante la articulación de sus usos públicos (Rodrigo, 2006; 2011), dentro de los cuales las asignaturas de Historia en la enseñanza obligatoria son cruciales, ya que "la escuela es justamente un ámbito donde las sociedades se disputan las memorias posibles sobre sí mismas" (Carretero, Rosa y González, 2006, 14).

Esto es lo que ha propiciado, en esta investigación, no centrarnos sólo en analizar e indagar sobre los límites del curriculum o la enseñanza de la historia en nuestros centros educativos, sino en señalar en este apartado alternativas prácticas y útiles para el profesorado y la comunidad educativa que busca completar esta "memoria fragmentada" de nuestros jóvenes y adolescentes, reconstruyendo una historia a veces parcial o sesgada. Porque, como plantean Rüsen (2007) o Pagès (2008) la historia es una forma elaborada de memoria.

La realización de acciones y propuestas curriculares destinadas a garantizar el derecho de la ciudadanía al conocimiento histórico veraz, no ya del pasado nacional lejano, sino de la devastación humana que sufrió el mundo desde la aparición del fascismo en la década de 1920, y de los genocidios que éste perpetró por razones raciales, ideológicas y culturales, es hoy en día una realidad con prestigio en los principales contenidos curriculares de países de la Unión Europea, en Estados Unidos y Canadá, en Argentina y Chile, en Australia y en Japón; y la memoria de las dictaduras 
se extiende a países como Ruanda o Sudáfrica con la voluntad de explicar la magnitud de los enfrentamientos civiles y los regímenes dictatoriales que los provocaron.

De hecho, la Recomendación relativa a la enseñanza de la Historia adoptada por el Comité de Ministros del Consejo de Europa del 31 de octubre de 2001 aparece un apartado dedicado a "Memoria y enseñanza" en el que se recomienda tomar medidas educativas para prevenir la repetición o la negación de acontecimientos devastadores que marcaron el siglo XX, haciendo una referencia explícita en el apartado dedicado a métodos de enseñanza a los "lugares de la memoria" y a la utilización de las fuentes orales, ofreciendo un espacio a puntos de vista y perspectivas de quienes "no están asociados a la historia escrita".

En buena parte del mundo, de Alemania a Inglaterra, de Italia a Francia, de Argentina a Polonia, el "recuerdo colectivo" de la "memoria traumática" asalta regularmente al presente, reclamando "deberes cívicos" de "rememoración"; invade y llena los espacios públicos y los centros de decisión política para "restituir" dignidades y "revisar" el pasado (Rodrigo, 2006).

De ahí que sean recomendables propuestas como las Unidades para la Recuperación de la Memoria Histórica (Díez Gutiérrez, 2009), realizadas como reelaboración o complemento a los libros de texto tradicionales, que tratan de recuperar esa parte de nuestra historia que ha quedado relativamente olvidada o silenciada en el curriculum escolar habitual. No obstante, es necesario seguir profundizando en aspectos apuntados en esta investigación sobre cómo aprende y asimila el alumnado estos contenidos, desde la visión de quienes son los protagonistas del proceso de aprendizaje y que son quienes filtran el currículum y los contenidos que se les ofrecen.

\section{Referencias bibliográficas}

ABÓS, A.L. (2004). La historia que nos enseñaron (1937-1975). Madrid: Foca.

AGUILAR FERnÁndeZ, P. (2008). Politicas de la Memoria. Memorias de la Política. Madrid: Alianza Editorial.

ÁLVAREZ OSÉS, J.A. Y OTROS. (2000). La guerra que aprendieron los españoles. República y guerra civil en los textos del bachillerato (1938-1983). Madrid: Libros de la Catarata.

APPLE, M. W (1986). Maestros y textos. Una economía politica de las relaciones de clase y sexo en educación. Barcelona: Paidós-MEC.

ARANZADI, J. (2009). Historia y nacionalismos en España hoy. En I. OLMOS, Y N. KEILHOLZ-RÜHLE (eds.): La cultura de la memoria. La memoria histórica en España y Alemania, (159-172). Madrid: Iberoamericana.

BERNECKER, W. (2009). Democracia y superación del pasado: sobre el retorno de la memoria histórica reprimida en España. EN I. OLMOS, Y N. KEILHOLZ-RÜHLE (eds.): La cultura de la memoria. La memoria histórica en España y Alemania, (5773). Madrid: Iberoamericana. 
CARRETERO, M.; ROSA, A. Y GONZÁLEZ, M.F. (Comp.). (2006). Enseñanza de la historia y memoria colectiva. Buenos Aires: Paidós.

CHARTIER, R. (2005). El presente pasado. Escritura de la historia, historia de lo escrito. México: Universidad Iberoamericana.

CUESTA, R. (2011a). Historia con memoria y didáctica crítica. Con-ciencia Social, 15, 15-30.

CUESTA, R. (2011b). Memoria, historia y educación: genealogía de una singular alianza. En Lomas, Carlos. (Coord.). Lecciones contra el olvido (Memoria de la educación y educación de la memoria) (163-196). Barcelona: Octaedro.

CUESTA, R. (2007). Los deberes de la memoria en la educación. Barcelona: Octaedro.

CUESTA, R. (1998). Clío en las aulas. La enseñanza de la Historia de España, entre reformas, ilusiones y rutinas. Madrid: Akal.

DÍEZ GUTIÉRREZ, E.J. (Dir.). (2009). Unidades Didácticas para la recuperación de la memoria histórica. León: Foro por la Memoria de León.

DÍEZ GUTIÉRREZ, E.J. (2007). La Globalización neoliberal y sus repercusiones en la educación. Barcelona: El Roure.

ERICE SEBARES, F. (2009). Guerras de la memoria y fantasmas del pasado. Uso y abusos de la memoria colectiva. Oviedo: Eikasia.

FAIRCLOUGH, N. (1992). Discourse and Social Change. Cambridge: Polity Press.

FAIRCLOUGH, N. (1992a). Critical Language Awareness. Londres: Longman.

FAIRCLOUGH, N. (2008). El análisis crítico del discurso y la mercantilización del discurso público: las universidades. Discurso \& Sociedad, 1, 170-185.

FREI, N. (2009). Procesos de aprendizaje en Alemania: el pasado nazi y las generaciones desde 1945. En I. Olmos, y N. KeILHOLZ-RÜHLE (eds.): La cultura de la memoria. La memoria histórica en España y Alemania, (89-106). Madrid: Iberoamericana.

GLASER, B. Y STRUSS, A. (1967). El desarrollo de la teoría fundada. Chicago, Illinois: Aldine.

JULIÁ, S. (2009). De hijos a nietos: Memoria e Historia de la Guerra Civil en la transición y en la democracia. En I. Olmos, y N. KeILHOLZ-RÜHLE (eds.): $L a$ cultura de la memoria. La memoria histórica en España y Alemania, (77-88). Madrid: Iberoamericana.

KINGMAN GARCÉS, E. (2012). Los usos ambiguos del archivo, la Historia y la memoria. Íconos: Revista de Ciencias Sociales, 42, 123-133.

KRIPPENDORF, K. (1990). Metodología de análisis de contenido. Teoría y práctica. Barcelona: Paidós. 
LEVI, P. (1986). I sommersi e i salvati.Turín: Einaudi.

MOLINERO, C. (2004). Memoria y Democracia. El País, 7 de noviembre de 2004.

MUDROVCIC, M.I. (2005). Historia, narración y memoria. Los debates actuales en filosofía de la historia. Madrid: Akal.

PÉREZ GARZÓN, J.S. Y OTROS, (2000). La gestión de la memoria. La historia de España al servicio del poder. Barcelona: Crítica.

REIG TAPIA, A. (2009). Cultura política y vía pacífica a la democracia. El miedo y el olvido en la transición española. En I. OLMOS, y N. KEILHOLZ-RÜHLE (eds.): La cultura de la memoria. La memoria histórica en España y Alemania, (107-128). Madrid: Iberoamericana.

ROBINSON, W.S. (1951). The logical structure ofanalytic induction. American Sociological Review, 16, 812-818.

RODRIGO, J. (2011). Acosada y desprestigiada: la "historia" vista desde la "memoria". Con-ciencia Social, 15, 133-140.

RÜSEN, J. (2007). Memory, history and the quest for the future. En CAJANI, L. (Ed.). History Teaching, Identities and Citizenship (13-34). CiCe, Stoke on Trent: Trentham Books.

SÁNCHEZ-LAFUENTE RECENA, J. (2008). ¿Qué tratamiento se da a la II República, a la Guerra Civil y al Franquismo en los libros de texto de historia de $4^{\circ}$ de ESO? En Acosta Bono, G.; Del Río SÁnchez, A. y VAlCuEnde Del Río, J.M. (Coords.). La recuperación de la memoria histórica: una perspectiva transversal desde las ciencias sociales (195-202). Sevilla: Fundación Centro de Estudios Andaluces (CENTRA).

SILVA, E. (2009). El trabajo de la Asociación para la Recuperación de la Memoria Histórica. En I. OLMOS, y N. KEILHOLZ-RÜHLE (eds.): La cultura de la memoria. La memoria histórica en España y Alemania, (173-184). Madrid: Iberoamericana.

TAYLOR, S. Y BOGDAN, R. (1992). Introducción a los métodos cualitativos de investigación. Barcelona: Paidós.

TODOROV, T. (2002). Memoria del mal, tentación del bien. Indagación sobre el siglo $X X$. Barcelona: Península.

TRAVERSO. E. (2007). El pasado, instrucciones de uso. Historia, memoria, política. Madrid: Marcial Pons.

VAN DIJK, T. A. (1997). Racismo y análisis crítico de los medios. Barcelona: Paidós.

VAN DIJK, T. A. (2008). Semántica del discurso e ideología. Discurso \& Sociedad, 2, 1, 201-261.

VINYES, R. (2011). Asalto a la memoria. Impunidades y reconciliaciones, símbolos y éticas. Barcelona: Los Libros del Lince. 
VINYES, R. (Coord.). (2004). Un futuro para el pasado. Barcelona: CEFID.

ZNANIECKI, F. (1934). The Method of Sociology. New York: Farrar and Rinehart.

\section{Fuentes electrónicas}

RODRIGO, J. (2006). La Guerra Civil: "Memoria", "Olvido", "Recuperación" e "Instrumentación". HISPANIA NOVA. Revista de Historia Contemporánea. 6. Recuperado el 1 de abril de 2012 en http://hispanianova.rediris. es/6/dossier/6d025.pdf

RUIZ-VARGAS, J.M. (2006). Trauma y memoria de la Guerra Civil y de la dictadura franquista. HISPANIA NOVA. Revista de Historia Contemporánea. 6. Recuperado el 19 de abril de 2011 en http://hispanianova.rediris.es/6/dossier/6d012.pdf

\section{Correspondencia con el autor}

Enrique Javier DÍEZ GUTIÉRREZ

Universidad de León

Facultad de Educación, 146. 24071 León

Teléfono: 678802722

e-mail: enrique.diez@unileon.es 